\title{
Industrial buyer-supplier partnerships: guidelines for a successful marriage
}

Laurens Debo, Dirk Van Oudheusden, Dirk Cattrysse, Katholieke Universiteit Leuven, Centre for Industrial Management, Research group Quantitative Techniques, Celestijnenlaan 300A, 3001 Heverlee, Belgium, tel : +32(0) 16/32.24.98, fax : +32(0)16/32.29.86, e-mail :

Laurens.Debo@cib.kuleuven.ac.be

Filip Roodhooft

Katholieke Universiteit Leuven, Departement of Applied Economic Sciences, Naamsestraat 69, 3000 Leuven, Belgium, tel : +32-(0) 16/32.69.22, fax : +32-(0)16/32.67.32

\begin{abstract}
Partnerships have recently been advocated as the way to gain a 'competitive advantage' in many industries. Strategic behaviour of partners, each having his own objectives and information, is an important factor for the management in a partnership. In this paper, we discuss these elements and illustrate their importance for inventory management of spare parts. We present the case of an airline company that has a 'partnership' agreement with a repairer for some of its spare parts. The airline company concludes a contract in which repair time performance is described. We identify the logistical objectives of both partners and information asymmetry between them. Combining elements of information economics and inventory management, we design an optimal contract for the airline company. We also discuss the importance of strategic behaviour for inventory management.
\end{abstract}

Keywords

Inventory Management, Supply Chain Management, Contracting 


\section{INTRODUCTION}

During recent years, strong global competitive pressures in output markets made a firm's supply management strategically important. Firms seek to get leverage from their suppliers by asking tailored services for their product. At the same time, customer service becomes important for suppliers, as their customers are more demanding. Apparently, an individual firm's competitive success does not only depend on the firm's own performance, but also on the performance of other firms that are in the same 'Supply Chain' (SC). Here, we see a Supply Chain as a series of trading relationships that sequentially add value to a product (Christy, 1994). One special kind of tight SC relationship is 'partnership'. In this paper, we will study logistic partnerships.

In the next section, we analyse the 'partnership' referring to literature and relying on own experience. We determine and discuss the most important elements of a partnership. In the following sections, we describe an industrial partnership between an engine repair shop and an airline company and we develop mathematical models for inventory management of the logistic partnership. In the last sections, we discuss shortly the implications for Supply Chain Management.

\section{LOGISTIC PARTNERSHIPS}

Recently, partnerships between buyer and supplier have received a lot of attention in the business press. Firms are moving away from traditional arm's length relationships to long-term collaborative relations with external business partners. A partnership however is not the only alternative to an arm's length relationship. Buyers and suppliers can choose from a portfolio of relationships (Bensaou, 1997). Once a partnership is established, both partners do not consider other potential partners anymore (for a long term). Partners exchange 'all relevant information' with each other and take decisions that are in the interest of both. Decisions taken on a partnership level are implemented locally without problems. This, however, is the description of an ideal, perfect partnership. Reported cases in literature and own industrial experience suggest that these assumptions are often too restrictive. Research of Lamming (1993) reveals that $46 \%$ of Nissan's existing and potential suppliers in the UK think that is reasonable to hide cost savings, despite of the 'very close' partner relationships between Nissan and its suppliers. Neuville (1997) describes the case of a 'partner supplier' in automobile industry who even sets up a strategy to disguise systematically shortcomings and cost reductions. An industrial purchaser, who made in the past partnership agreements with some of his key suppliers, tells us that too much product and process knowledge transfer to his supplier is advantageous on short term but may lead to situations where the suppliers takes over the buyer's business function and becomes a competitor. These observations indicate that information and incentive asymmetries are present, even in a partnership (Corbett, 1997).

For the logistic management of a partnership, it is not realistic to adopt a perspective of a central co-ordinator, who focuses on enhancing the performance of 
the total SC, in (re-)designing the SC. A more promising approach is to agree on a SC incentive structure or contract, such that, in the extent possible, each party fully internalises all consequences of his decisions, and has all information available to support that decision. This principle only holds when both partners are risk neutral, which seems to be reasonable in a logistic context (Corbett, 1997).

In this paper, we will study the design of a contract between an airline company and a repairer.

\section{DESCRIPTION OF A PARTNERSHIP BETWEEN AN AIRLINE COMPANY AND A REPAIR SHOP}

The airline company's jet engines of its aeroplanes are quite expensive and have a limited duration of life due to failing components. A defective engine, however, can be repaired and its duration of life extended. In the jet engine repair shop, the engine is examined and the defective components are identified, repaired or changed. The whole repair process takes some weeks, denoted by the TAT, Turn Around Time. Let us call the airline company and the engine repair shop studied in this case, Birdline and Allfix respectively.

\subsection{Birdline's logistic system}

Jet engines show exponential failure behaviour. This means that the time between two successive failures (TBF) is exponentially distributed and independent of other TBFs. As the TAT takes some days, Birdline takes some extra engines in stock (spare engines). This is expensive: spares have to be insured and they tie up capital and space. The order cost of reparation is negligible with respect to the holding costs. Therefore, Birdline adopts a one-for-one replenishment policy: each time a jet engine is defective, it is replaced by a spare and immediately sent to Allfix. If no spare is available, Birdline cannot use the aeroplane (Aircraft On Ground, or AOG situation). It has to wait until the next repaired spare engine arrives from Allfix.

\subsection{Allfix's logistic system}

Allfix manages a repair shop. The TAT is the sum of a technology determined repair time (e.g. due to the chemical treatment of the surface of turbine blades, due to the testing of electronic components and so on) and queuing time (due to machine capacity, workforce or material constraints). However, if Birdline has an AOG situation, Allfix can considerably shorten the repair time for one jet engine. Therefore, Allfix can temporarily add capacity (an extra shift, weekend work), change priorities in queues or loan jet engine from an other operator, pass this engine to Birdline and give back the repaired engine to the operator later on. Each of these actions increases Allfix's servicing costs. 


\subsection{Incentive conflict, information asymmetry and contracts}

It is clear that Allfix and Birdline have, to some degree, conflicting objectives. Allfix prefers not to shorten lead-times. Birdline however prefers the shortest possible lead-time. Currently, Birdline and Allfix are negotiating a contract in which repair time performance is described. The following policy is considered (Pol): if there are one or more spares in Birdline's stock, Allfix repairs Birdline's engines within the TAT, determined by the state of his repair shop at that moment. Whenever there are No Spares in Stock (NSS), Birdline alarms Allfix, who will instantaneously repair every engine, failing during a NSS situation (and thus causing an AOG situation)*. Figure 1 illustrates the NSS and AOG situations.

Note that following Pol results in an AOG situation that is instantaneously resolved. Of course, Pol is an approximation of reality in which an AOG repair will have a positive duration (some days), but this is small compared to the TAT ( 40 days). Although the AOG duration is very short, an AOG causes a considerable cost for Birdline (e.g. cancelled flight).

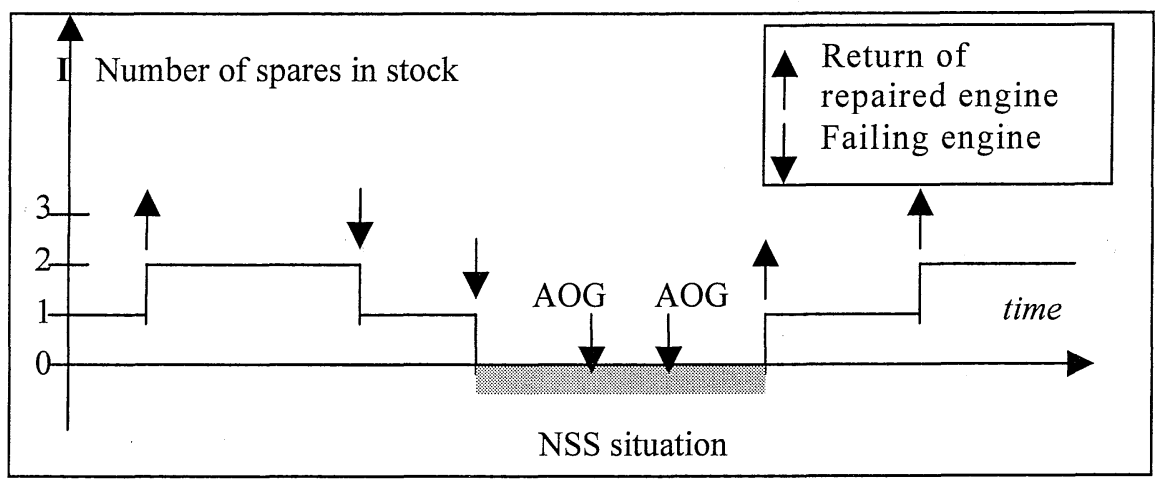

Figure 1: Birdline's inventory levels, NSS and AOG situations.

Allfix accepts to repair under Pol, but his extra servicing cost will depend on the number of spares, S, Birdline keeps in stock and on his private information over the additional cost per AOG repair, c. The less spares Birdline stocks, the more frequently NSS and AOG situations will occur, thus the more frequently Allfix incurs an additional cost, c.

Birdline seeks an optimal way to compensate Allfix's costs. It can be proved that this can be achieved by offering Allfix a menu of contracts (Laffont, 1993), here denoted in the form of the couples, $\left(S_{\mathrm{j}} ; \mathrm{P}\left(S_{\mathrm{j}}\right)\right)$, from which Allfix may choose $S_{\mathrm{j}}$ and his premium, $\mathrm{P}\left(\mathrm{S}_{\mathrm{j}}\right)$. The sequence of actions that will take place is the following:

\footnotetext{
* In fact, the contract stiputales a 'maximum repair time' in NSS situations, but since this complicates the mathematical analysis, we will consider an immediate repair (maximum repair time is zero), without losing fundamental insights of the contracting model.
} 
1. Birdline has a priori estimation of $\mathrm{c}$ : $\operatorname{Prob}\left(\mathrm{c}=\mathrm{c}_{\mathrm{i}}\right)=\mathrm{p}_{\mathrm{i}}, \mathrm{i}=1,2, \ldots \mathrm{m}, \mathrm{c}_{\mathrm{k}}<\mathrm{c}_{1}$ for $1 \leq \mathrm{k}<\mathrm{l} \leq \mathrm{m}$.

2. Birdline proposes a premium $\left(S_{\mathrm{j}} ; \mathrm{P}\left(S_{\mathrm{j}}\right)\right)$ for $S_{\mathrm{j}}$ stocked spares and premium $\mathrm{P}\left(S_{\mathrm{j}}\right), \mathrm{j}=1,2, \ldots \mathrm{n}$ (menu of contracts).

3. Allfix chooses $(\mathrm{S}, \mathrm{P}(\mathrm{S}))$ maximising its net revenues and knowing its own costs per AOG, $\widetilde{\mathrm{c}}_{\mathrm{i}}: \operatorname{Max}_{S} \mathrm{P}(S)-\operatorname{Cost}_{\mathrm{Allfix}}\left(S, \widetilde{\mathrm{c}}_{\mathrm{i}}\right)$.

4. From then on Birdline stocks $S$ spares and pays a fixed premium $P(S)$ to Allfix.

Note that Allfix can easily verify that Birdline takes S spares in stock. As it repairs all Birdline's engines, it only performs an AOG repair if already $\mathrm{S}$ engines are being repaired.

In the following sections we will discuss Birdline's optimal design of the menu of contracts. Table 1 summarises all costs, revenues and their drivers.

Table 1 Logistic costs and their drivers for Allfix and Birdline.

\begin{tabular}{|c|c|c|c|c|}
\hline & Cost & Driver & Revenues & Driver \\
\hline Birdline & $\begin{array}{l}\text { Holding } \\
\text { Missed flights } \\
\text { Premium }\end{array}$ & $\begin{array}{l}\text { Per spare, } \\
\text { per time unit } \\
\text { Per AOG } \\
\text { Fixed }\end{array}$ & $X$ & $X$ \\
\hline Allfix & AOG repair & Per AOG & Premium & Fixed \\
\hline
\end{tabular}

\section{A MATHEMATICAL MODEL FOR A CONTRACT BETWEEN ALLFIX AND BIRDLINE}

\subsection{The inventory problem}

Let us adopt the notation of Table 2. The number of spares in stock at an arbitrary moment in time, I $(0 \leq \mathrm{I} \leq \mathrm{S})$, using policy Pol, and exponential TBF and TAT distributions, can be modelled by means of a birth-death process with, for state $\mathrm{I}=\mathrm{i}$, arrival rate $\lambda_{\mathrm{i}}=\lambda$ and service rate $\mu_{\mathrm{i}}=\mathrm{i} \mu$. We use this Markov chain to determine the mean number of $A O G$ situations:

$$
\mathrm{N}(S)=\mathrm{E}\left(\mathrm{N}_{\mathrm{AOG}}\right)=S \mu \mathrm{Pr}(\mathrm{I}=0) \frac{\lambda}{S \mu}=\lambda / \sum_{k=0}^{S}\left(\frac{\mu}{\lambda}\right)^{\mathrm{k}} \frac{S !}{(S-k) !} .
$$

Note that $\mathrm{N}(0)=\lambda$ and $\mathrm{N}(S)$ is decreasing in $S$. 
Table 2 Notation for the inventory model.

\begin{tabular}{llll}
\hline Symbol & Description & Symbol & Description \\
\hline$S$ & Total number of spares & $\mathrm{c}^{\prime}$ & Cost/AOG (Birdline) \\
$\mathrm{f}_{\lambda}(\mathrm{t})=\lambda \mathrm{e}^{-\lambda \mathrm{t}}$ & Distribution of TBF & $\mathrm{c}$ & Cost/AOG repair (Allfix) \\
$\mathrm{f}_{\mu}(\mathrm{t})=\mu \mathrm{e}^{-\mu \mathrm{t}}$ & Distribution of TAT & $\mathrm{N}_{\mathrm{AOG}}$ & Number of AOGs \\
$\mathrm{h}$ & Holding cost rate & $\mathrm{I}$ & Number of spares in stock \\
\hline
\end{tabular}

\subsection{The contracting problem}

In order to study the contracting problem, we will assume that the interaction with other customers of Allfix does not influence the system. We will compare the performance of an incentive contract, as described in Section 3.3, with two other modes of co-operation: perfect co-operation and co-operation with a fixed price contract.

\section{Co-operation with an Incentive Contract (IC)}

We will follow the theory outlined by Laffont (1993) for designing a supply contract. Birdline solves the following program to determine $P_{\mathrm{i}}=\mathrm{P}\left(S_{\mathrm{i}}\right)$ and $S_{\mathrm{i}}$ :

$$
\begin{aligned}
& \underset{P_{i}, S_{i}}{\operatorname{Min}} \sum_{\mathrm{i}} \mathrm{p}_{\mathrm{i}}\left(P_{\mathrm{i}}+\mathrm{h} * S_{\mathrm{i}}+\mathrm{c}^{\prime *} \mathrm{~N}\left(S_{\mathrm{i}}\right)\right) \\
& \text { s.t. } \\
& P_{\mathrm{i}}-\mathrm{c}_{\mathrm{i}} \mathrm{N}\left(S_{\mathrm{i}}\right) \geq 0 \quad(\mathrm{IR}) \\
& P_{\mathrm{i}}-\mathrm{c}_{\mathrm{i}} \mathrm{N}\left(S_{\mathrm{i}}\right) \geq P_{\mathrm{k}}-\mathrm{c}_{\mathrm{i}} \mathrm{N}\left(S_{\mathrm{k}}\right) \quad(\mathrm{IC}) \\
& P_{\mathrm{i}} \geq 0 \quad S_{\mathrm{i}}=0,1,2,3, \ldots \quad \mathrm{i}, \mathrm{k}=1,2, \ldots, \mathrm{m} .
\end{aligned}
$$

We assume that Birdline and Allfix are risk neutral. Allfix will accept the contract only if he raises a positive amount with it. This is modelled by the Incentive Rationality constraints (IR). Birdline designs a contract for each type $i$ (with cost $\left.\mathrm{c}_{\mathrm{i}}\right)$ in such a way that type $\mathrm{i}$ prefers the contract $\left(\mathrm{S}_{\mathrm{i}} ; \mathrm{P}_{\mathrm{i}}\right)$ to the contract $\left(\mathrm{S}_{\mathrm{k}} ; \mathrm{P}_{\mathrm{k}}\right)$. This is modelled by the Incentive Compatibility constraints (IC). The program results in couples $\left(\mathrm{P}_{\mathrm{i}}{ }_{\mathrm{IC}} ; \mathrm{S}_{\mathrm{i}}{ }^{\mathrm{IC}}\right)$ which are presented to Allfix. Of course, it is possible that some $\mathrm{P}_{\mathrm{i}}{ }^{\mathrm{IC}}$ and $\mathrm{S}_{\mathrm{i}}{ }^{\mathrm{IC}}$ are the same for a class of Allfix types because $S$ is an integer variable. In this way, we obtain the menu of contracts $\left(S_{j}{ }_{j} ; P_{j}{ }^{I C}\right), j=1,2, \ldots n$.

\section{Co-operation with Fixed Price Contract (FPC)}

In this case of co-operation, Allfix tries to exaggerate as much as possible its costs per AOG. Therefore, Birdline solves: $\operatorname{Min}_{S} \mathrm{~h}^{*} S+\left(\mathrm{c}^{\prime}+\mathrm{c}_{\mathrm{m}}\right) * \mathrm{~N}(S)$; with optimal solution $\mathrm{S}^{\mathrm{FPC}}$. 


\section{Perfect Co-operation (PC)}

Under perfect co-operation, each partner has full access to all relevant information, including cost $\mathrm{c}_{\mathrm{i}}$. They solve: $\operatorname{Min}_{S_{\mathrm{i}}} \mathrm{h}^{*} S_{\mathrm{i}}+\left(\mathrm{c}_{\mathrm{i}}+\mathrm{c}^{\prime}\right) * \mathrm{~N}\left(S_{\mathrm{i}}\right) \mathrm{i}=1,2, \ldots, \mathrm{n}$; with optimal solution $\mathrm{S}_{\mathrm{i}}^{\mathrm{PC}}$.

Total Supply Chain costs under each co-operation mode $\alpha=\{\mathrm{FPC}, \mathrm{IC}, \mathrm{PC}\}$ : $\mathrm{C}^{\alpha}=\sum_{\mathrm{i}} \mathrm{p}_{\mathrm{i}}\left(\mathrm{h}^{*} \mathrm{~S}_{\mathrm{i}}^{\alpha}+\left(\mathrm{c}_{\mathrm{i}}+\mathrm{c}^{\prime}\right) * \mathrm{~N}\left(\mathrm{~S}_{\mathrm{i}}^{\alpha}\right)\right)$.

Obviously the following inequalities are valid: $\mathrm{C}^{\mathrm{FPC}} \geq \mathrm{C}^{\mathrm{IC}} \geq \mathrm{C}^{\mathrm{PC}}$.

\subsection{A numerical example}

Even without taking into account the specific structure of (2), we can solve it easily by a Mixed Integer Linear Programming model. Suppose that $\mathrm{h}=0.35, \lambda=1 / 27.5$, $\mu=1 / 40, c^{\prime}=25, c_{i}=\{5,7.5,10,12.5, \ldots, 52.5$ (20 values) $\}, p_{i}=\{0.05,0.05,0.05$, $0.05, \ldots, 0.05$ (20 values) $\}$. Then, we can show that it is optimal for Birdline to propose the following incentive contract to Allfix: $(S ; \mathrm{P}(S))=\{(1 ; 0.391)$, $(2 ; 0.338),(3 ; 0.228),(4 ; 0.084)\}$. Depending on its real $\mathrm{c}_{\mathrm{i}}$, Allfix will choose one contract. Table 3 shows $\mathrm{S}_{\mathrm{i}}^{\mathrm{PC}}, \mathrm{S}_{\mathrm{i}}^{\mathrm{IC}}$ and $\mathrm{S}^{\mathrm{FPC}}$. For $\mathrm{c}_{\mathrm{i}} \in[7.5] \cup[20 ; 30] \cup[50 ; 52.5]$, the IC takes one spare more than the PC contract, for $\mathrm{c}_{\mathrm{i}}=5$, the FPC contract takes 2 more spares and for $\mathrm{c}_{\mathrm{i}} \in[7.5 ; 30]$ the FPC contract takes 1 more spare than the PC contract. The total Supply Chain costs are: $\mathrm{C}^{\mathrm{FPC}}=1.299, \mathrm{C}^{\mathrm{IC}}=1.273, \mathrm{C}^{\mathrm{PC}}=1.252$.

Table 3: Comparison of $\mathrm{S}^{\alpha}\left(\mathrm{c}_{\mathrm{i}}\right)$ for $\alpha=\{\mathrm{FPC}, \mathrm{IC}, \mathrm{PC}\}$.

\begin{tabular}{llllllllllllll}
\hline$c_{i}$ & 5 & 7.5 & 10 & $\ldots$ & 17.5 & 20 & $\ldots$ & 30 & 32.5 & $\ldots$ & 47.5 & 50 & 52.5 \\
\hline $\mathrm{S}_{\mathrm{i}}^{\mathrm{PC}}$ & 1 & 1 & 2 & $\ldots$ & 2 & 2 & $\ldots$ & 2 & 3 & $\ldots$ & 3 & 3 & 3 \\
$\mathrm{~S}_{\mathrm{i}}^{\mathrm{IC}}$ & 1 & 2 & 2 & $\ldots$ & 2 & 3 & $\ldots$ & 3 & 3 & $\ldots$ & 3 & 4 & 4 \\
$\mathrm{~S}^{\mathrm{PPC}}$ & 3 & 3 & 3 & $\ldots$ & 3 & 3 & $\ldots$ & 3 & 3 & $\ldots$ & 3 & 3 & 3 \\
\hline
\end{tabular}

\section{FURTHER RESEARCH}

The model developed in this paper helps to gain insight in the logistic 'games' that are played by members of a Supply Chain. This kind of research not only needs empirical verification of the effect of different co-operation modes on inventory levels but also further theoretical developments. The considered one shot contracts can be extended to dynamic situations reflecting many real situations. More realistic elements of the inventory policy, like a positive AOG repair time, can be introduced. A risk adverse repairer or airline company can be modelled and other contractual settings as Repairer Managed Inventory studied. Other kinds of information asymmetry between can be considered such as information about the real demand rate (failing rate) or repair time. Moral hazard (where one party cannot 
observe the effort exerted by the other) can be studied besides adverse selection, see also Corbett (1997). Incorporating these elements, however, will considerably complicate mathematical analysis.

\section{CONCLUSION}

We studied three co-operation modes between two firms for spare parts management and conclude that the logistic management of a Supply Chain, in which there is more than one 'stakeholder', is sensitive to the strategic behaviour of the stakeholders. Insights in the role of information and incentive asymmetry and in ways to cope with it are valuable for logistic managers, certainly in the new competitive environment where outsourcing and partnerships set the order of the day. However, a lot of fieldwork and academic research has yet to be done. This area of Supply Chain Management seems to be extremely interesting for both practitioners and academics.

\section{REFERENCES}

Bensaou, B. and Venkatrama, N. (1996) Not by Partnership Alone: Managing a Portfolio of Relationships. Working Paper INSEAD, 30, 1-14.

Christy, D.P. and Grout, J.R. (1994) Safeguarding supply chain relationships. International Journal of Production Economics, 36, 233-42.

Corbett, C.J. (1997) Stochastic inventory systems in a supply chain with asymmetric information, cycle stocks, safety stocks, and consignment stock. Working Paper Anderson School of Management, UCLA, 1-33.

Laffont, J.J. and Tirole, J. (1993) A theory of incentives in procurement and regulation. The MIT Press, Cambridge.

Lamming, R. (1993) Beyond partnership: strategies for innovation and lean supply, Prentice-Hall, New York.

Neuville, J.P. (1997) La stratégie de la confiance, le partenariat industriel observé depuis le fournisseur. Sociologie du Travail, 3, 297-319. 